\title{
Ensino Religioso: expectativas e perspectivas discentes em formação docente
}

\author{
Religious Education: expectations and perspectives from \\ the students in teacher training
}

\section{Remí Klein}

Doutor em Teologia, na área de Religião e Educação, professor adjunto da Universidade do Vale do Rio dos Sinos (Unisinos) e da Escola Superior de Teologia (Faculdades EST), São Leopoldo, RS - Brasil, remiklein@terra.com.br

\section{Resumo}

Este trabalho avalia a importância da capacitação em Metodologia de Ensino Religioso nos cursos de licenciatura em Pedagogia, uma vez que, pela legislação vigente em âmbitos nacional e estadual, não é exigida nenhuma formação específica, além da habilitação docente propriamente dita, para lecionar a referida disciplina na educação infantil e nos anos iniciais do ensino fundamental. $\mathrm{O}$ artigo abarca o embasamento legal sobre o assunto e o confronta com uma pesquisa de campo, envolvendo a própria prática docente, bem como a atuação de outros docentes e a participação de discentes na disciplina em cursos de Licenciatura em Pedagogia em Institutos de Ensino Superior (IES) na região metropolitana de Porto Alegre.

Palavras-chave: Ensino Religioso. Legislação. Formação docente. Metodologia. Práxis educativa. 


\section{Abstract}

This article evaluate the importance of capacity building in Methodology of Religious Education in the licentiate courses in Pedagogy, once no specific training is required beyond teacher training itself, according to current national and state legislation, to teach the referred discipline in kindergarten and in the initial years of basic education. The paper deals with the legal foundations of the subject and confronts it with a field research, involving the teaching practice itself, as well as the work of other professors and the participation of students in the referred pedagogical discipline in licentiate courses of Pedagogy in Higher Education Institutions in the metropolitan region of Porto Alegre.

Keywords: Religious Education. Legislation. Teacher training. Methodology. Educative practice.

\section{Considerações preliminares}

Pela Constituição Federal, de 1988, o Ensino Religioso como componente curricular está assegurado no ensino fundamental (Artigo 210, Parágrafo $1^{\circ}$ ), sendo que, por algumas constituições estaduais, como a do Rio Grande do Sul, de 1989, esta oferta fica assegurada também no ensino médio (Artigo 209, Parágrafo $1^{\circ}$ ). A LDB, Lei n. 9.394/96 (BRASIL, 1996), o assegura no ensino fundamental (Artigo 33, com nova redação dada ao referido artigo pela Lei n. 9.475/97, BRASIL, 1996) e o Conselho Nacional de Educação, pelo seu Parecer 04/98 (BRASIL, 1998), ao estabelecer as Diretrizes Curriculares Nacionais para o ensino fundamental, define a Educação Religiosa como uma das dez áreas de conhecimento. Assim, gradativamente, também se abrem espaços em estados e em municípios para concursos e para a criação de cargo específico de professor de Ensino Religioso.

Há, pois, entrementes, o devido amparo legal para esse componente curricular, mesmo que sua efetiva implementação ainda não aconteça nos diferentes sistemas de ensino e em todas as escolas, desde sua inclusão nas propostas curriculares (Projeto Político-Pedagógico e Planos de Estudo), até a prática no cotidiano da sala de aula. Há, também, a definição de uma proposta curricular em diferentes níveis, com Parâmetros Curriculares 
Nacionais elaborados e editados pelo Fórum Nacional Permanente do Ensino Religioso (Fonaper) em 1997, bem como referenciais curriculares para o Ensino Religioso em diversos sistemas estaduais e municipais de ensino, além de propostas de planos de estudos de Ensino Religioso e de diversos materiais didáticos disponibilizados por diferentes editoras, subsídios estes que visam a servir de orientação para a elaboração dos planos de estudo das escolas no tocante a este componente curricular.

Contudo, um terceiro pilar é fundamental e imprescindível para que o Ensino Religioso efetivamente se concretize, conforme a proposta assegurada em lei, com a nova redação dada ao Artigo 33 da LDB pela Lei n. 9.475/97, que em seu caput estabelece que:

O ensino religioso, de matrícula facultativa, é parte integrante da formação básica do cidadão, constitui disciplina dos horários normais das escolas públicas de ensino fundamental, assegurado o respeito à diversidade cultural religiosa do Brasil, vedadas quaisquer formas de proselitismo (BRASIL, 1997).

Trata-se de assegurar uma formação específica nesta área aos professores nos seus diferentes âmbitos. Neste sentido, deve-se observar, em primeiro lugar, o que estabelece a própria LDB, Lei n. 9.394/96, no tocante à formação de professores, quando, em seu Artigo 62, refere que:

a formação de professores para atuar na educação básica farse-á em nível superior, em curso de licenciatura, de graduação plena, em universidades e institutos superiores de educação, admitida, como formação mínima para o exercício do magistério na educação infantil e nas quatro primeiras séries do ensino fundamental, a oferecida em nível médio, na modalidade Normal (BRASIL, 1996).

A LDB coloca a ênfase na formação como professor, seja em curso na modalidade Normal, seja em curso de Licenciatura, mas não determina (embora tampouco impeça) que seja oferecido ou proposto curso específico para formação de professores de Ensino Religioso. Contudo, a nova redação dada ao Artigo 33 da LDB pela Lei n. 9.475/97 normatiza que os sistemas de ensino "regulamentarão os procedimentos para a definição dos conteúdos do ensino religioso e estabelecerão as normas para a habilitação dos professores" (BRASIL, 1997). 
Qualquer oferta de curso de formação para professores de Ensino Religioso deve necessariamente observar esse embasamento legal dado pelas Constituições, pela LDB e por pareceres e resoluções dos sistemas de ensino, seja do Conselho Nacional de Educação ou dos Conselhos Estaduais e Municipais de Educação, de acordo com o sistema a que está vinculado o estabelecimento de ensino. Portanto, a oferta de curso não pode conduzir a qualquer forma de proselitismo; deve assegurar o respeito à diversidade cultural religiosa, ser necessariamente inter-religiosa e não restrita a uma determinada denominação religiosa, o que, por analogia, deve valer também para a oferta da disciplina de Metodologia de Ensino Religioso, em curso de Licenciatura em Pedagogia.

Para assegurar essa área de conhecimento e esse componente curricular na formação básica do cidadão, é imprescindível uma formação específica de professores. Por isso, diante dos avanços reconhecidos e assegurados em relação ao Ensino Religioso pelas Constituições, pela LDB e pelas Diretrizes Curriculares Nacionais do CNE, causou estranheza quando, em 1999, o próprio CNE (BRASIL, 2001), ao se ocupar com o assunto da formação de professores para o Ensino Religioso, aprovou o Parecer 97/99, concluindo que:

[...] não lhe compete autorizar, nem reconhecer, nem avaliar cursos de licenciatura em ensino religioso, cujos diplomas tenham validade nacional [...] competindo aos Estados e municípios organizarem os conteúdos do ensino religioso nos seus sistemas de ensino e as normas para a habilitação e admissão dos professores (BRASIL, 1999).

O referido Parecer tomou como argumentos a separação entre Igreja e Estado e o preceito constitucional da liberdade e da pluralidade religiosa, conforme o Artigo 19 da Constituição Federal e com base na Lei n. 9.475/97, que, em seu Parágrafo $1^{\circ}$, determina que "[...] os sistemas de ensino regulamentarão os procedimentos para a definição dos conteúdos e estabelecerão as normas para a habilitação e admissão de professores" (BRASIL, 1997). O Parecer remeteu a competência e a responsabilidade aos sistemas estaduais e municipais de ensino, gerando impactos e impasses para a formação específica de professores de Ensino Religioso por meio de cursos de Licenciatura, com resoluções e pareceres distintos nos diferentes sistemas de ensino. 
A título de exemplificação, transcrevemos a seguir as regulamentações de alguns Estados ${ }^{1}$ no tocante à formação docente para a atuação no Ensino Religioso na educação infantil e nos anos iniciais do ensino fundamental, as quais são bastante semelhantes, a saber, não prevendo formação específica além da formação docente propriamente dita:

[...] Art. $6^{\circ}$ - Para o exercício da docência no ensino religioso, exigirse-á, em ordem de prioridade: I - nos anos iniciais: a - graduação em Curso de Pedagogia, com habilitação para o magistério dos anos iniciais; b - graduação em Curso Normal Superior; c - habilitação em Curso de nível médio - modalidade Normal, ou equivalente [...] (PARANÁ, 2006).

[...] Art. $1^{\circ}$ - São habilitados a lecionar Ensino Religioso em escolas integrantes do Sistema Estadual de Ensino os professores: I - titulados em nível médio ou superior para a docência na educação infantil e/ou nos quatro anos iniciais do ensino fundamental, para atuar nesses níveis da escolarização [...] (RIO GRANDE DO SUL, 2000).

[...] Art. $5^{\circ}$ - A formação para a docência na Educação Religiosa poderá ser conseguida: $\int 1^{\circ}$. Admitir-se-á a docência na Educação Religiosa por professores com o Curso Normal de Nível Médio, para classes de Educação Infantil e de $1^{a}$ a $4^{a}$ séries do Ensino Fundamental e com o curso ao nível de Licenciatura Curta para as classes de $5^{\mathrm{a}}$ a $8^{\mathrm{a}}$ séries do Ensino Fundamental, acrescidos, nos dois casos, de capacitação especifica em Educação Religiosa, com duração não inferior a 120 horas [...] (RONDỐNIA, 2003). [...] Art. $8^{\circ}$ - Consideram-se habilitados para o exercício do magistério do Ensino Religioso, nos quatro primeiros anos do ensino fundamental: os portadores de diploma de magistério de nível médio, modalidade Normal; os licenciados em Pedagogia, com habilitação para o magistério do $1^{\circ}$ ao $4^{\circ}$ ano do Ensino Fundamental; os portadores de diploma de Curso Normal Superior; os docentes licenciados portadores de Curso de Especialização lato sensu em Ensino Religioso, ou pós-graduação stricto sensu na área. $\int 1^{\circ}$ Nos anos iniciais do Ensino Fundamental das escolas da rede pública do Sistema Estadual de Ensino, o Ensino Religioso pode ser ministrado pelos próprios professores responsáveis pela classe, sendo trabalhado de forma transversal, ou em forma de projeto de trabalho, ou outra modalidade similar de integração curricular conforme o disposto no projeto político

\footnotetext{
${ }^{1}$ Conforme mapeamento disponível em JUNQUEIRA; KLEIN, 2008. p. 221-243.
} 
pedagógico das escolas. $\int 2^{\circ}$ - Por questões de foro íntimo o docente pode recusar-se a ministrar Ensino Religioso, devendo a unidade escolar ou a rede de ensino substituí-lo naquele componente curricular [...] (MACEIÓ, 2002).

[...] Art. $2^{\circ}$ - Habilitam-se para lecionar o Ensino Religioso em escolas públicas, nas quatro séries iniciais do Ensino Fundamental, os professores que apresentarem: a) Diploma de nível médio na modalidade normal; b) Diploma de Curso Normal Superior ou de Curso de Licenciatura para o Magistério das séries iniciais do Ensino Fundamental [...] (MARANHÃO, 2004).

[...] Art. $5^{\circ}$ - Considera-se apto para o exercício do magistério do Ensino Religioso, o professor: I. graduado em Curso Normal Superior. [...] (SERGIPE, 2003).

[...] Art. $2^{\circ}$ - Consideram-se habilitados para o exercício do magistério de ensino religioso, nas quatro primeiras séries do ensino fundamental: a) os portadores de diploma de magistério em normal médio; b) os portadores de licenciatura em Pedagogia, com habilitação no magistério de $1^{\mathrm{a}}$ a $4^{\mathrm{a}}$ séries do ensino fundamental [...] Art. $4^{\circ}$ - Nas séries iniciais do ensino fundamental das escolas da rede estadual, os conteúdos de ensino religioso serão ministrados pelos próprios professores responsáveis pela classe. Parágrafo único - Os conteúdos serão trabalhados transversalmente sob a responsabilidade e organização do professor [...] (SÃO PAULO, 2001).

Diante da inexistência de formação específica de professores para a atuação no Ensino Religioso nos diferentes níveis de ensino, diferentes IES no país começaram ou continuaram se articulando e se empenhando na oferta de cursos de Ciências da Religião com Licenciatura em Ensino Religioso e com outras alternativas de formação inicial e continuada para professores de Ensino Religioso, com cursos de extensão, com ênfase de Ensino Religioso em cursos de Licenciatura em Pedagogia e com cursos de especialização, de 400 horas, bem como com a oferta da disciplina de Metodologia de Ensino Religioso nos cursos de Pedagogia, que é o enfoque do presente artigo.

\section{Oferta da disciplina de metodologia de ensino religioso nos cursos de pedagogia}

Considerando que a normatização nacional e as normatizações estaduais não preveem formação específica em Ensino Religioso para 
a atuação docente na educação infantil e nos anos iniciais do ensino fundamental, o presente artigo aborda a questão da capacitação que os estudantes recebem em sua formação docente nos cursos de Licenciatura em Pedagogia e o quanto a disciplina de Metodologia de Ensino Religioso pode se constituir num espaço mínimo e básico de formação. Trata-se de uma abordagem a partir de um projeto de pesquisa intitulado "O Ensino Religioso na formação docente: um olhar sobre a Metodologia de Ensino Religioso em cursos de Licenciatura em Pedagogia", desenvolvido pelo autor do presente artigo em vinculação com a sua atuação docente no Programa de Pós-Graduação em Teologia, na área de Concentração em Religião e Educação, na Faculdades EST, em São Leopoldo/RS, entre julho de 2007 e dezembro de 2009.

A pesquisa em questão abarcou o embasamento legal sobre o assunto e o confrontou com uma pesquisa de campo, envolvendo a própria prática docente na referida disciplina na Unisinos, desde 1999, bem como a atuação de outros docentes e a participação de discentes nessa disciplina pedagógica em cursos de Licenciatura em Pedagogia em IES da região metropolitana de Porto Alegre e numa IES de Curitiba. A pesquisa de campo se desenvolveu por meio do levantamento on-line e da análise quanto à oferta da referida disciplina, com base em depoimentos em forma de memoriais de discentes dessa disciplina, no início do semestre (em termos de preconceitos e de expectativas) e no fim do semestre (em termos de aprendizagens significativas e de perspectivas de atuação docente), visando a analisar que auxílio a referida disciplina proporciona aos estudantes em seu processo de formação docente, com vistas ao trabalho com o componente curricular do Ensino Religioso na educação infantil e nos anos iniciais do ensino fundamental, na perspectiva da proposta estabelecida no Artigo 33 da LDB (Lei n. 9.394/96) pela nova redação dada pela Lei n. 9.475/97.

A metodologia de pesquisa foi prioritariamente qualitativa, baseando-se na busca de dados bibliográficos relativos à legislação e em pesquisa de campo com levantamento e análise de dados a partir de documentos disponíveis e disponibilizados sobre a disciplina de Metodologia de Ensino Religioso e, sobretudo, de depoimentos de discentes desta disciplina, fruto de suas experiências, expectativas e perspectivas. Utilizou-se pesquisa bibliográfica, análise documental e memoriais descritivo-analíticos, em que discentes da referida disciplina descreveram de forma reflexiva e analítica a sua própria experiência. Para esse aspecto, exercitou-se a proposta 
de pesquisa etnocartográfica, sobretudo com base nas propostas de Marli André (etnografia) e Suely Rolnik (cartografia) (ANDRÉ, 1989). Como processo investigativo, foi integrada a própria experiência profissional do docente-pesquisador, em confronto com a experiência de outros docentes e discentes da referida disciplina em IES na região metropolitana de Porto Alegre e também de uma IES de Curitiba. ${ }^{2} \mathrm{O}$ referencial teórico da pesquisa esteve, assim, no diálogo entre as áreas de Teologia/Religião e Pedagogia/ Educação, com um recorte e uma delimitação para o Ensino Religioso e, dentro do mesmo, com um olhar especial para a questão da formação docente para esta área de conhecimento.

Quanto às questões metodológicas, a opção pelo memorial descritivo-analítico como uma metodologia de pesquisa partiu do pressuposto de que o resgate das memórias, o seu registro e a reflexão sobre elas constituem a identidade pessoal e também profissional docente, conforme palavras de Madalena Freire Weffort (1996, p.9):

todas estas lembranças quando resgatadas, socializadas entre outras e, assim, apropriadas, ganham status de memória. Memória que alicerça a consciência histórica, política e pedagógica desse sujeito. O desafio é formar, informando e resgatando num processo de acompanhamento permanente, um educador que teça seu fio para apropriação de sua história, pensamento, teoria e prática (WEFFORT, 1996, p. 9).

Assim, o docente-pesquisador e autor do presente artigo refere-se a olhares em perspectivas e a novos olhares 'em formação' (KLEIN, 2007, p. 38-51), no sentido de repensaro processo de formação docente em estreita vinculação entre o ensino e a pesquisa, num confronto entre a teoria e a prática, tanto na formação inicial como na formação continuada, como se pode ver no testemunho de vida do educador Paulo Freire: "A gente se forma como educador, permanentemente, na prática e na reflexão sobre a prática” (FREIRE, 1991, p. 58).

\footnotetext{
${ }^{2}$ A denominação da atividade pedagógica é bastante variável: na Unisinos era desenvolvida em forma da disciplina de Metodologia de Ensino: Ensino Religioso, sendo de quatro créditos; entrementes, a proposta curricular está organizada em forma de Programa de Aprendizagem, sendo a Atividade Acadêmica correspondente denominada Sujeitos, Espaços e Tempos: Ensino Religioso, inicialmente de dois créditos e atualmente de quatro créditos. No Unilasalle, a disciplina denomina-se Fundamentos de Ensino Religioso, sendo de quatro créditos. Na PUCPR, denomina-se Metodologia de História e Ensino Religioso, de quatro créditos. No projeto de pesquisa e no presente artigo opta-se pela denominação genérica de Metodologia de Ensino Religioso.
} 
Ou seja, não basta que o olhar de pesquisador seja acadêmico e pedagógico; ele precisa apreender e captar o cotidiano e o invísível, ou seja, ser etnocartográfico. O conhecimento torna-se, assim, autobiográfico e existencial. Nesse sentido, Maria Isabel da Cunha refere-se ao trabalho com narrativas no ensino e na pesquisa, ao afirmar que

trabalhar com narrativas na pesquisa e/ou no ensino é partir para a desconstrução/construção das próprias experiências, tanto do professor/pesquisador como dos sujeitos da pesquisa e/ ou do ensino. Exige que a relação dialógica se instale criando uma cumplicidade de dupla descoberta. Ao mesmo tempo em que se descobre no outro, os fenômenos revelam-se em nós (CUNHA, 1998, p. 39).

Dada a abrangência da pesquisa, o presente artigo se limita aos dados dos memoriais descritivo-analíticos de discentes, para conhecer suas experiências e expectativas (no início de semestre) e suas perspectivas (no fim de semestre) em sua formação docente quanto à disciplina de Metodologia de Ensino Religioso no curso de Licenciatura em Pedagogia e, por extensão, quanto a este componente curricular nas escolas de educação básica de sua possível atuação (atual ou futura).

Num primeiro momento, são trazidos alguns depoimentos em termos de experiências relacionadas ao Ensino Religioso, com base em registros feitos pelos estudantes no fórum de discussão após a vivência de um jogo "Minha história, tua história", na primeira aula da atividade acadêmica de Sujeitos, Espaços e Tempos: Ensino Religioso em 2009. O enunciado no fórum era o seguinte: "Socializem aqui suas lembranças marcantes em termos de seu processo educativo-religioso e suas reflexões a partir do jogo feito em aula!" A seguir, outro enunciado em forma de diagnóstico solicitava que expressassem suas expectativas em relação ao Ensino Religioso na educação básica, bem como em relação à formação e à atuação específica nesta área e, em especial, à atividade acadêmica em curso.

Assim, os depoimentos a seguir foram extraídos de memoriais de estudantes do curso de Pedagogia da Unisinos do primeiro e do segundo semestres de 2009, constantes no fórum de discussão do Programa de Aprendizagem Sujeitos, Espaços e Tempos: Ensino Religioso, sob a docência do autor do presente artigo. 
A questão de como lidar com a diversidade religiosa e de como abordá-la em sala de aula e no componente curricular de Ensino Religioso foi o aspecto mais ressaltado, o que, pois, precisa ser proporcionado como enfoque na formação docente, constituindo-se numa dimensão muito mais epistemológica do que pedagógica e metodológica propriamente dita. Outra tônica refere-se à questão pedagógica e metodológica propriamente dita, em termos de referencial curricular, proposta de plano de estudos e subsídios metodológicos:

Busco nesta disciplina subsidios para fundamentar a construção dos Planos de Estudo em Ensino Religioso na escola na qual atuo como professora e coordenadora pedagógica, visto que a acessibilidade a materiais que abordem a diversidade de crenças não é abundante. Busco também trocar muitas ideias de atividades para sugeri-las em minha prática escolar, buscando aprimorar nosso trabalho docente.

Quanto às expectativas, gostaria que fosse discutido o que deve ser ensinado nas aulas de Ensino Religioso, uma vez que eu entendo que a aula de Ensino Religioso não deva ter o caráter de uma aula de catequese. Não sei muito sobre como dar uma aula de Ensino Religioso, até porque é a primeira vez que isso é abordado no curso. Como nunca lecionei, então só posso me espelhar nas aulas de Ensino Religioso enquanto aluna. Além de aprender qual o conteúdo que hoje é exigido pelos Parâmetros Curriculares, também exemplos de algumas dinâmicas, projetos já elaborados e que deram certo, exemplos daquilo que seja uma boa aula de Ensino Religioso e que de fato ajude o aluno a crescer como um ser humano em sua totalidade.

No ano de 2007 tive uma ótima experiência em Ensino Religioso com uma turma de $5^{a}$ série em escola municipal. Fazíamos dinâmicas de grupo, jogos, palestras, nos lembrávamos das datas religiosas, epercebi com muita alegria que os alunos respeitam muito a diversidade religios a que existe num grupo.

Um dia uma colega me questionou: isto é Ensino Religioso? Parece mais uma aula de cidadania. E a partir de então fiquei com uma grande dúvida: o que realmente importa numa aula de Ensino Religioso com credos tão diferentes? Como falar, por exemplo, numa história biblica sem manifestar a minha crença, a minha interpretação da história? Desejo que nossas aulas possam me ajudar e orientar neste sentido.

Minhas expectativas em relação a esta atividade são as melhores possiveis, visto que tenho uma turma de $2^{\circ}$ ano, com a atividade de Ensino Religioso, e não recebo nenhuma orientação da escola sobre que temas devo trabalhar com eles... Acredito que nossas aulas possam me ajudar bastante. 
Diante das informações que nos foram passadas sobre a disciplina Sujeitos, Espaços e Tempos, tenho como uma das principais expectativas para o men aperfeiçoamento na formação docente um contato mais próximo e verdadeiro dos discentes. Para que essa aproximação possa de fato acontecer, é necessário que os professores resgatem com os alunos as suas próprias histórias, para, a partir disso, trabalhar seus medos, anguistias e alegrias, fazendo das nossas aulas momentos prazerosos e de trocas de experiências. Acredito que esta atividade acadêmica nos ajudará nessa busca de aproximação com os alunos, mostrando-nos diferentes modos/maneiras de concretizar um maior envolvimento com o corpo discente.

Minhas expectativas são muitas, mas minha prioridade será a de conseguir dar o primeiro passo para abandonar os velhos métodos educativos para que assim possa intermediar o conhecimento de Ensino Religioso com meus alunos, de forma prazerosa e lúdica, assim como foi o jogo da aula passada. Pois, como tive uma péssima experiência religiosa em meu processo educativo, não quero que meus alunos passem pelo mesmo terror psicológico a que fui submetida.

Minhas expectativas são as melhores, pois sou professora de $4^{a}$ série $\left(5^{\circ}\right.$ ano) e trabalho com Ensino Religioso, mas sinto falta de qualificação e muitas vezes fico pensando, procurando, pesquisando atividades para desenvolver nessas aulas.

Nestes relatos a partir das experiências discentes e de suas expectativas em relação à atividade acadêmica, percebemos muitos preconceitos quanto ao referido componente curricular em sua experiência escolar, tanto como estudantes como enquanto docentes já em atuação, e uma grande expectativa quanto à ressignificação do Ensino Religioso na proposta curricular das escolas.

No fim do semestre foi solicitado aos estudantes que registrassem no fórum de discussão, em forma de memorial descritivo-analítico, suas perspectivas a partir dessa atividade acadêmica, em termos de sua formação docente, quanto ao componente curricular do Ensino Religioso nas escolas de educação básica de sua possível atuação (atual ou futura). Eis alguns depoimentos de estudantes registrados nos memoriais constantes nos fóruns de discussão:

A partir do trabalho desenvolvido durante as aulas, repensei minha prática pedagógica, não só em relação ao Ensino Religioso, como também de uma forma geral. Desse modo, entendo que minha prática será mais rica e efetiva, pois o embasamento sobre a religiãa e sobre o histórico 
do Ensino Religioso me deu outro olhar sobre ele, passei a valorizá-lo mais, a pensar outros modos de constituir minha prática, de torná-la prazerosa e construtiva para meus alunos. Com certeza as dinâmicas me serão de suma importância e me ajudarão a trabalhar com a diferença e a diversidade, respeitando a subjetividade de cada indivíduo.

Após esse pequeno período de discussões e reflexões, percebo que tinha uma visão do Ensino Religioso e hoje tenho outra. Acreditava que o Ensino Religioso era trabalhar trechos bíblicos, pois foi assim que eu, como aluna, fui trabalhada. Hoje sei que devemos respeitar as diversidades entre as religiões, vivenciar com os alunos a solidariedade, o respeito, a convivência em harmonia. O professor, ao ministrar uma aula de Ensino Religioso, deveria ter formação, preparo, pois os professores trabalham esse ensino sem estarem preparados e acabam não trabalhando o real sentido desse importante ensinamento de vida para o aluno. Foi muito boa essa experiência, abriu meus olbos!

Avalio como uma disciplina que abriu minha mente sobre o Ensino Religioso que deve ser passado para os nossos alunos. Um Ensino Religioso que respeite a diversidade e que abra o horizonte da criança para o que deve ser realmente importante como a fraternidade, a paze 0 respeito pelo próximo. Vejo como importante sabermos também sobre a legislação que existe sobre o Ensino Religioso e que devemos ser bastante "cuidadosos e respeitosos" com a diversidade religiosa de nossas criancas, pois não podemos ficar só no discurso, devemos fazer com que os alunos entendam efetivamente essa diversidade e dela participem.

Posso afirmar que vou sair deste Programa de Aprendizagem com outra visão de Ensino Religioso, pois durante as atividades aprendi muito sobre as leis, a história e a prática desta área de conhecimento. Acredito que neste momento já posso trabalhar o Ensino Religioso de forma mais consciente e segura, sabendo de forma criativa planejar, sempre respeitando as diversas religioes. Pessoalmente afirmo que desconbecia as possibilidades de se fazer um bom trabalho de Ensino Religioso com os alunos, pois sentia até certo medo de abordar o assunto, inclusive agora dou mais importância para o tema e reconheço sua fundamental presença na sala de aula.

Em minha opinião, percebo que este Programa de Aprendizagem contribuiu em vários aspectos, principalmente no meu olhar sobre o Ensino Religioso. Por essa razãa, agora me vejo dentro da sala de aula tratando do Ensino Religioso mais confortavelmente, pois, afinal de contas, os seus assuntos levam a melhorar a conduta dos educandos em um convivio social pleno de respeito, de maior aproximação, uma questão de formação de identidade consciente [...]. 
Os depoimentos falam por si e atestam a diferença que a atividade acadêmica de Metodologia de Ensino Religioso representa na concepção dos estudantes quanto a este componente curricular na educação básica, ressignificando suas experiências e dissipando os preconceitos, em confronto com a proposta atual assegurada na LDB, em seu Artigo 33, alterado pela Lei n. 9.475/97, em que este "constitui parte integrante da formação básica do cidadão", devendo nele ser "assegurado o respeito à diversidade cultural religiosa do Brasil, vedadas quaisquer formas de proselitismo" (BRASIL, 1997). Com o referido projeto de pesquisa apresentado por meio do presente artigo espera-se, pois, que mais IES passem a integrar em sua proposta de formação docente a atividade acadêmica da Metodologia de Ensino Religioso e que este componente curricular possa receber, consequentemente, o seu devido tratamento epistemológico, pedagógico e metodológico em nossas escolas.

\section{Referências}

ANDRÉ, M. E. D. A. de. Etnografia da prática escolar. 4. ed. Campinas, SP: Papirus, 1995.

BRASIL. Lei n. 9.394, de 20 de dezembro de 1996. Estabelece as diretrizes e bases da educação nacional. Diário Oficial [da] República Federativa do Brasil, Poder Legislativo, Brasilia, DF, 23 dez. 1996. p. 27833. Disponível em: <http:// www6.senado. gov:br/legislacao/ListaTextoIntegral.action?id=75723>. Acesso em: 23 jul. 2009.

. Presidência da República. Lei n. 9.475/97, de 22 de julho de 1997. Alteração, normas, correlação, facultatividade, disciplina escolar, religião, estabelecimento de ensino, ensino fundamental, território nacional, competência, sistema de ensino, fixação, conteúdo, disciplina escolar, religião. Diário Oficial [da] República Federativa do Brasil, Brasilia, Congresso Nacional, 23 jul. 1997. Coluna 2, p. 15824. Disponível em: < http://www6.senado.gov.br/legislacao/ListaNormas.action?tipo_norma $=$ LE I\&numero $=009475 \&$ data $=1997 \&$ SUBMIT1 $=$ Pesquisar $>$. Acesso em: 21 jan. 2010.

. Conselho Nacional de Educação. Parecer n. 04/98 - CEB, de 29 de janeiro de 1998. Diretrizes Curriculares Nacionais para o Ensino Fundamental. Diário Oficial [da] República Federativa do Brasil, 29 jan. 1998. Disponível em: <http://portalsme.prefeitura.sp.gov.br/Documentos/ BibliPed/TextosLegais/LegislacaoEducacional/Parecer_CNE_CEB_04_98_ InstituiDiretrizesCurricularesNacionaisEnsinoFundamental.pdf $>$. Acesso em: 21 jan. 2010. 
. Conselho Nacional de Educação. Parecer n. 97/99, de 6 de abril de 1999. Formação de Professores para o Ensino Religioso nas Escolas Públicas de Ensino Fundamental. Diário Oficial [da] República Federativa do Brasil, Brasilia-DF, 6 abr. 1999. Disponível em: <http://www.crmariocovas.sp.gov.br/ pdf/diretrizes_p0596-0601_c.pdf>. Acesso em: 10 jan. 2010.

. Conselho Nacional de Educação. Resolução CNE/CEB n. 2, de 11 de setembro de 2001. Diário Oficial [da] Republica Federativa do Brasil, Brasília, DF, 14 set. 2001. Seção 1E, p. 39-40. Disponível em: <http://portal.mec.gov.br/ cne/arquivos/pdf/CEB0201.pdf>. Acesso em: 30 nov. 2009.

CUNHA, M. I. da. O professor universitário na transição de paradigmas. Araraquara, SP: JM, 1998.

FÓRUMNACIONAL PERMANENTE DO ENSINO RELIGIOSO. Parâmetros Curriculares Nacionais: ensino religioso. 9. ed. São Paulo: Ave Maria, 2009.

FREIRE, P. A educação na cidade. São Paulo: Cortez, 1991. p. 58.

JUNQUEIRA, S. R. A.; KLEIN, R. Aspectos referentes à formação de professores de Ensino Religioso. Revista Diálogo Educacional, v. 8, n. 23, p. 221-243, 2008.

KLEIN, R. O. Práxis do Ensino Religioso: olhares em perspectivas e novos olhares 'em formação'. In: WACHS, M. C. et al. (Org.). Práxis do Ensino Religioso na escola. São Leopoldo: Sinodal, 2007. p. 38-51.

MACEIÓ. O Conselho Estadual de Educação de Alagoas. Resolução n. 003/2002, 04 de julho de 2002. Regulamenta o Art. 33 da Lei 9.394/96 alterado pela Lei 9.475/97 no âmbito do Sistema Estadual de Ensino de Alagoas e define normas correlatas. Disponível em: < http://www.educacao.al.gov.br/servicos/legislacao/ resolucoes-conselhos/RESOLUCaO $\% 20 \mathrm{No} \% 20003 \% 20$ regulamenta $\% 20$ o $\% 20$ artigo \%2033\%20da\%20lei\%209.394-96.doc/>. Acesso em: 5 jan. 2010.

MARANHÃO. Lei n. 8.197, 6 de dezembro de 2004. Dispõe sobre o Ensino Religioso nas Escolas Públicas do Ensino Fundamental, no âmbito do Estado do Maranhão, em conformidade com o disposto na Lei Federal n. 9.475/97 e na Lei de Diretrizes e Bases na Educação Nacional (Lei n. 9.394/96), e dá outras providências. Disponível em: <http://www.ma.gov.br/2007/12/13/Pagina14.htm> Acesso em: 8 dez. 2009.

PARANÁ. Conselho Estadual de Educação. Deliberação n. 01/06-CEE/PR 11 fev. 2006. Inserção dos conteúdos de Ensino Religioso. Disponível em: <http:/ / www.cee.pr.gov.br/arquivos/File/pdf/Pareceres2009/CEB/pa_ceb_540_09. pdf>. Acesso em: 9 jan. 2010. 
RIO GRANDE DO SUL. Conselho Estadual de Educação. Resolução n. 256, 22 de março de 2000. Regulamenta a habilitação de professores de Ensino Religioso e os procedimentos para a definição dos conteúdos desse componente curricular. Disponível em: < http://www.mp.rs.gov.br/infancia/legislacao/id3176.htm> Acesso em: 8 jun. 2007.

ROLNIK, S. Cartografia sentimental: transformações contemporâneas do desejo. São Paulo: Estação Liberdade, 1989.

RONDÔNIA. Secretaria de Estado da Educação. Resolução n. 108/03, 15 de dezembro de 2003. Estabelece normas para a definição dos conteúdos curriculares e para a habilitação e admissão de docentes da Educação Religiosa, nas instituições escolares do Sistema Estadual de Ensino, e dá outras providências. Disponível em: < http://www.cee.ro.gov.br/Resolucoes/Resolu\%E7\%E3o\%20108.03.htm>. Acesso em: 20 dez. 2009.

SÃO PAULO. Conselho Estadual de Educação. Deliberação n. 16/2001, 28 jul. 2001. Regulamenta o Art. 33 da Lei 9.394/96. Disponível em: <http://www.ceesp. sp.gov.br/Deliberacoes/de_16_01.htm>. Acesso em: 21 dez. 2009.

SERGIPE. Conselho Estadual de Educação. Resolução n. 019/2003/CEE, 6 nov. 2003. Dispõe sobre normas para a oferta do Ensino Religioso e a habilitação e admissão de seus professores, nas escolas de ensino fundamental da rede pública. Disponível em: <http://www.seed.se.gov.br/portais/cee/arquivos/ Resolucao_019-2003-CEE_08-05-2003.pdf>. Acesso em: 6 jan 2010.

WEFFORT, M. F. et al. Observação, registro, reflexão: instrumentos metodológicos I. 2. ed. São Paulo: Espaço Pedagógico, 1996.

Recebido: 07/03/2010

Received: 03/07/2010

Aprovado: $25 / 05 / 2010$

Approved: 05/25/2010 